\title{
Hyper- and Hypoglycemic Coma among Diabetic Patients in Arar, Northern Saudi Arabia
}

Nada Kareem S Alruwaili ${ }^{1}$, Yasamiyan Mohammed A Alanazi ${ }^{1}$, Seham Mohammed Alanazi ${ }^{2}$, Wafaa Kareem S Alruwaili ${ }^{1}$, Almaha Ahmad Abdulaziz Alali ${ }^{1}$, Zaynab Hussain M Almukalaf ${ }^{1}$, Noof Saud J Alenezi ${ }^{1}$, Shouq Saud J Alanazi ${ }^{1}$, Razan Mohammed G Aldahmashi ${ }^{1}$

1 Faculty of Medicine, Northern Border University, Arar, 2 Almaarefa Colleges for Science and Technology, College of Medicine, Riyadh, KSA

\begin{abstract}
Background: Diabetic coma is a reversible form of coma found in people with diabetes mellitus. It is a medical emergency. Three different types of diabetic coma are identified; Severe low blood sugar in a diabetic person, diabetic ketoacidosis (usually type 1) advanced enough to result in unconsciousness from a combination of a severely increased blood sugar level, dehydration and shock and exhaustion, hyperosmolar non ketotic coma (usually type 2) in which an extremely high blood sugar level and dehydration alone are sufficient to cause unconsciousness. The aim of this study was to determine the prevalence of diabetic coma among the studied diabetic patients and to illustrate the relationship between type of diabetic coma and type of DM, period of diabetes and place of management of coma. Methods: A cross-sectional study was carried out on 113 diabetic patients (both type I and II DM) in Arar city, Northern Saudi Arabia, KSA, during the period from 1 December to 30 June 2017. Data collected by a pre-designed online self-administered questionnaire.

Results: The mean age of participants was $35.62( \pm 21.62)$ years and $67.3 \%$ were females. The prevalence of diabetic coma among the studied diabetic patients was $57.5 \%$ and the type of coma was hypoglycemic in $70.7 \%$ and hyperglycemic in $29.3 \% .42 .1 \%$ of hyperglycemic coma patients had type I diabetes and $57.9 \%$ had type II. While, $50 \%$ of hypoglycemic coma patients had type I diabetes. On the hand, $21.1 \%$ of hyperglycemic coma patients treated in the emergency department, $10.5 \%$ admitted to the hospital and $68.4 \%$ treated at home. While $34.8 \%$ of hypoglycemic coma patients treated in the emergency department, $6.5 \%$ admitted to the hospital and $58.7 \%$ treated at home. There was no significant relation between type of $\mathrm{DM}$ and type of diabetic coma $(\mathrm{P}=$ $0.562)$ or between period of diabetes and type of diabetic coma $(\mathrm{P}=0.060)$. Conclusion: The prevalence of diabetic coma among the studied diabetic patients was 57.5\% and the type of coma was hypoglycemic in 70.7\% and hyperglycemic in $29.3 \%$. We recommend to spread awareness of the diabetic patients about causes and manifestations of diabetic coma to guard against it. Also we recommend a large scale and more detailed researches.
\end{abstract}

Keywords: Hyper and Hypoglycemic Coma; Type I and Type II diabetes; Diabetes emergency; Arar, Northern Saudi Arabia

\section{INTRODUCTION}

The complications of diabetes mellitus are far less common and less severe in people who have wellcontrolled blood sugar levels. They represent the major causes of morbidity and mortality that are associated with this chronic metabolic disorder ${ }^{[1]}$.

The term diabetic coma refers to the diagnostical dilemma posed when a physician is confronted with an unconscious patient about whom nothing is known except that they have diabetes ${ }^{[2]}$.

At the present time three main types and one 'mixed' type of diabetic coma are recognized known as hypoglycemia, ketoacidosis and hyperosmolar hyperglycemic state ${ }^{[3]}$.

Easily the most common variety of diabetic coma is that associated with gross and excessive overproduction of 'ketone bodies' which-because they are also strongly acidic lead to the characteristic • syndrome of 'ketoacidosis' ${ }^{[4]}$.

The aim of this study was to determine the • prevalence of diabetic coma among the studied diabetic patients and to illustrate the relationship between type of diabetic coma and type of DM, period of diabetes and place of management of coma.

\section{PARTICIPANTS AND METHODS}

A cross-sectional study was carried out on 113 diabetic patients (both type I and II DM) in Arar city, Northern Saudi Arabia, KSA. This study was conducted during the period from 1 December 2017 to 30 June 2017, on general population in Arar, KSA. Data collection: by a pre-designed online questionnaire which was distributed among the population. It was self-administered by participants after a brief introduction or explanation of the idea of the research. The questionnaire included the relevant questions to collect data about:

Socio-demographic characteristics of the participants including age, marital status and educational status

If the patient has DM or previous diabetic coma or both. 
- Questions about risk factors, symptoms and complications.

\section{Statistical analysis}

Collected data were coded and analyzed using statistical package for the social sciences (SPSS, version 15). Descriptive statistics for the prevalence and quantitative variables was used. Relationship between type of diabetic coma, type of DM, period of diabetes and place of management of coma was determined using the chi-square test. P-value of less than 0.05 was considered statistically significant.

\section{Ethical considerations}

Permission to conduct the study was obtained from the Research and Ethics Committee at the College of Medicine, Northern Border University, Arar, Saudi Arabia. The questionnaire had a brief introduction explaining the aims and significance of the study.

\section{RESULTS}

As represented in table (1); the mean age of participants was $35.62( \pm 21.62)$ years old and $67.3 \%$ were females. $69.9 \%$ were married and $64.6 \%$ were highly educated.

The prevalence of diabetic coma among the studied diabetic patients was $57.5 \%$ and the type of diabetic coma among the studied diabetic patients was hypoglycemic in $70.7 \%$ and hyperglycemic in $29.3 \%, 53.1 \%$ were type II DM and $46.9 \%$ type I. About 38\% had diabetes for more than 10 years.

There was no significant correlation between type of DM and type of diabetic coma $(\mathrm{P}=0.562)$ or between period of diabetes and type of diabetic coma $(\mathrm{P}=0.060)$.Regarding the relationship between type of diabetic coma, type of DM, $42.1 \%$ of hyperglycemic coma patients had type I diabetes and $57.9 \%$ had type II. While $50 \%$ of hypoglycemic coma patients had type I diabetes and 50\% had type II. On the hand, $21.1 \%$ of hyperglycemic coma patients treated in the emergency department, $10.5 \%$ admitted to the hospital and $68.4 \%$ treated at home. While $34.8 \%$ of hypoglycemic coma patients treated in the emergency department, $6.5 \%$ admitted to the hospital and $58.7 \%$ treated at home. (Table 3).

Table (1): Socio demographic characteristics among studied diabetic patients, Arar, KSA

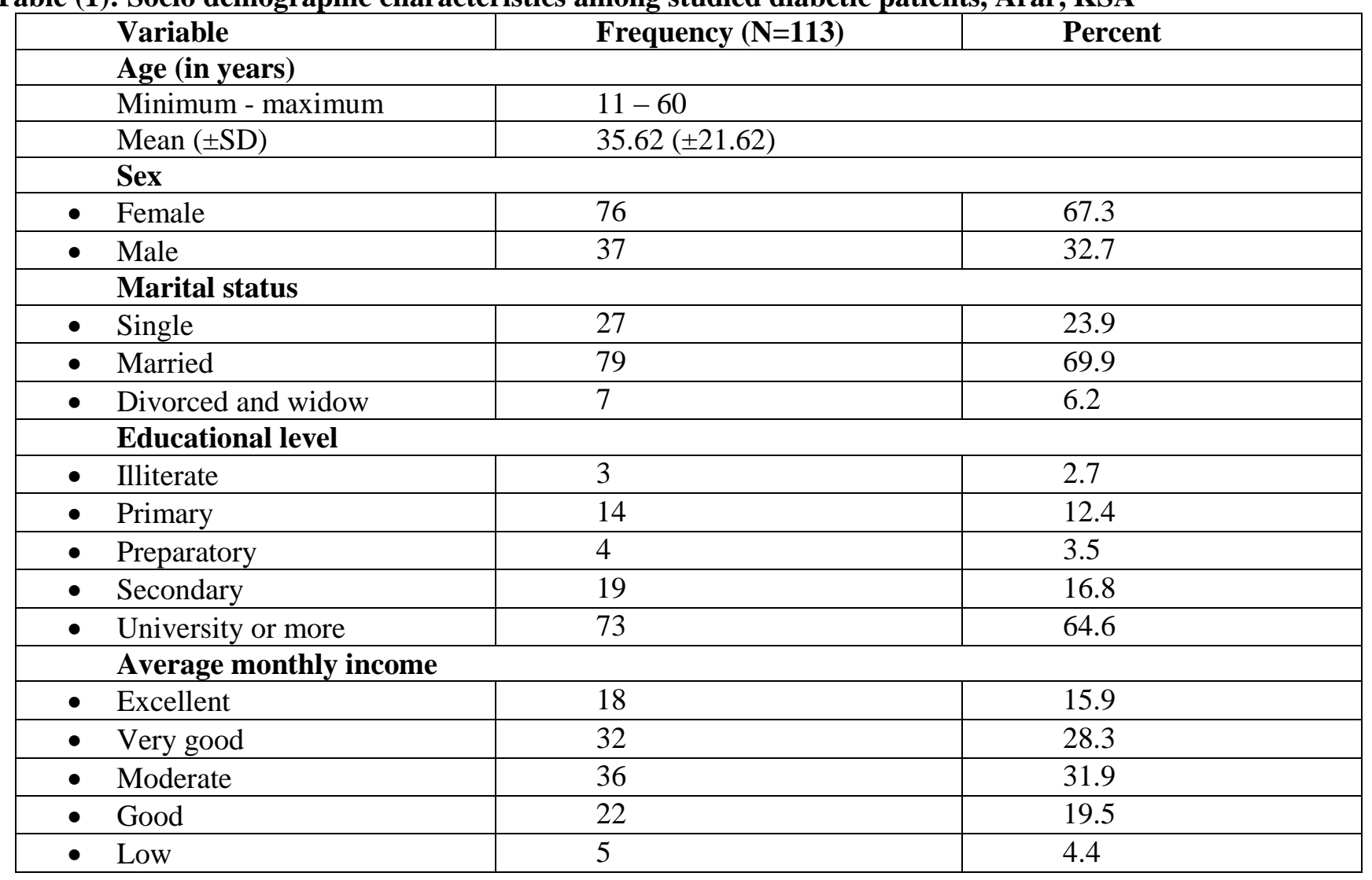


Table (2): diabetes related characteristics, other chronic diseases, Smoking, obesity and receiving health education about diabetic coma among studied diabetic patients, Arar, KSA

\begin{tabular}{|l|l|l|}
\hline Variable & Frequency (N=113) & Percent \\
\hline Type of DM & & \\
\hline Type II & 60 & 53.1 \\
\hline Type I & 53 & 46.9 \\
\hline Period of diabetes (in years) & & \\
\hline$<1$ & 7 & 6.2 \\
\hline $1-$ & 31 & 27.4 \\
\hline $5-10$ & 16 & 14.2 \\
\hline$>10$ & 43 & 38.1 \\
\hline Don't know & 16 & 14.2 \\
\hline Diabetic complications & 46 & 40.7 \\
\hline Type of diabetic complications & & \\
\hline Diabetic food & 3 & 2.7 \\
\hline Diabetic neuropathy & 12 & 10.6 \\
\hline Diabetic retinopathy & 27 & 23.9 \\
\hline Diabetic nephropathy & 4 & 3.5 \\
\hline Other chronic diseases & & \\
\hline Hypertension & 25 & 22.1 \\
\hline Hypercholesterolemia & 8 & 7.1 \\
\hline Cardiac diseases & 4 & 3.5 \\
\hline Psychological diseases & 2 & 1.8 \\
\hline Cerebrovascular stroke & 1 & .9 \\
\hline Smoking & 14 & 12.4 \\
\hline Obesity & 37 & 32.7 \\
\hline Receiving health education about diabetic coma & & \\
\hline Yes & 90 & 79.6 \\
\hline No & 23 & 20.4 \\
\hline
\end{tabular}

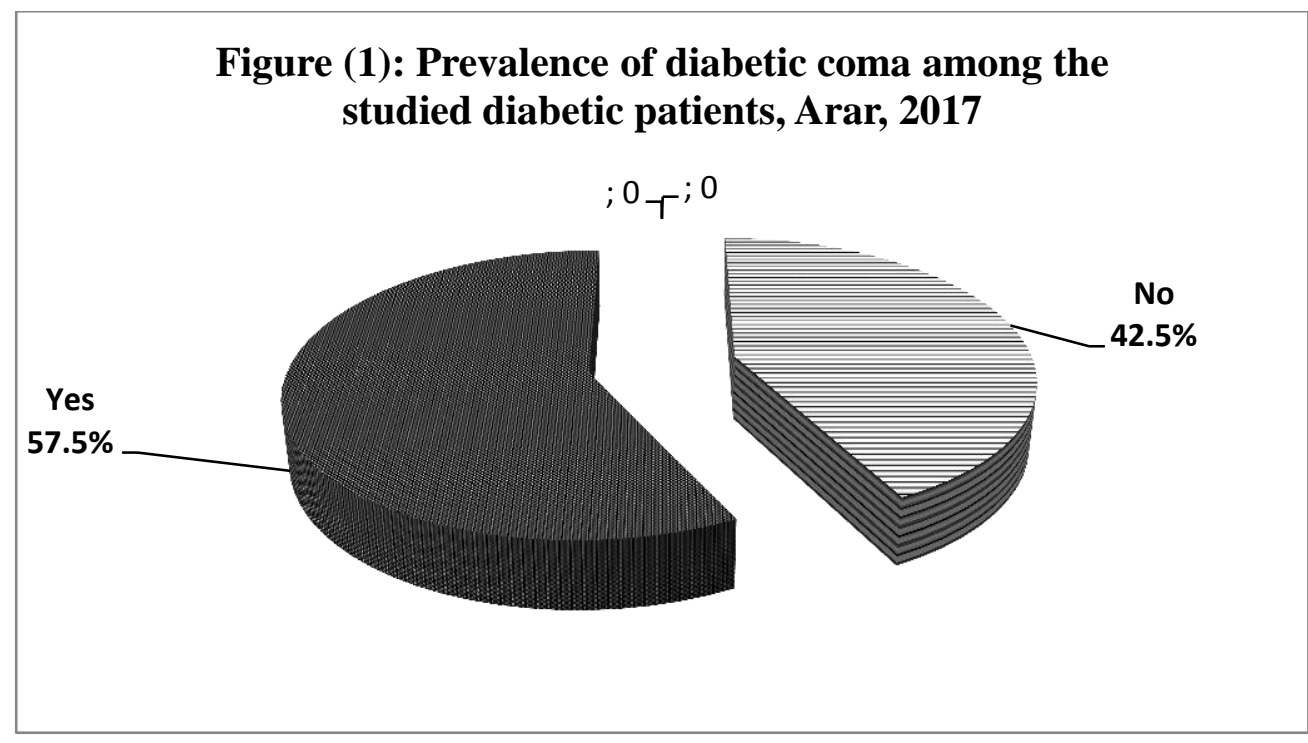


Figure (2): Type of diabetic coma among the studied diabetic patients, Arar, 2017

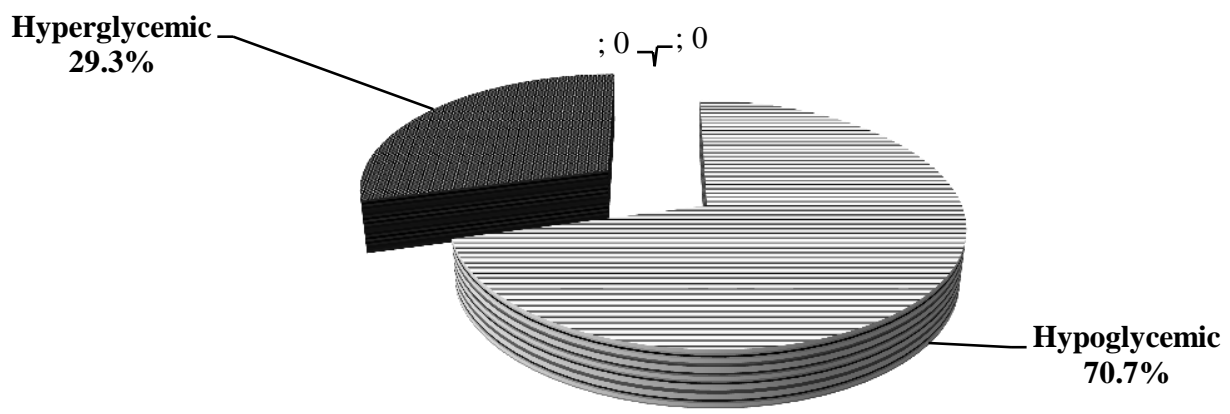

Table (2): Type of diabetic coma, eating before coma and management of coma

\begin{tabular}{|c|c|c|c|}
\hline to & 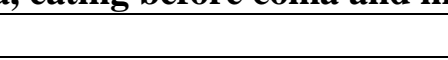 & Frequency $(\mathrm{N}=113)$ & Percent (\%) \\
\hline \multirow{2}{*}{ Diabetic coma } & - $\mathrm{No}$ & 48 & 42.5 \\
\hline & - $\quad$ Yes & 65 & 57.5 \\
\hline \multirow[t]{2}{*}{ Type of Coma } & - Hyperglycemic & 19 & 29.2 \\
\hline & - Hypoglycemic & 46 & 70.7 \\
\hline \multirow[t]{2}{*}{ Eating before coma } & - $\mathrm{No}$ & 58 & 89.2 \\
\hline & - Yes & 7 & 10.8 \\
\hline \multirow[t]{3}{*}{ Management of coma } & $\begin{array}{l}\text { In the emergency } \\
\text { department }\end{array}$ & 20 & 30.8 \\
\hline & Admitted to the hospital & 5 & 7.7 \\
\hline & Managed at home & 40 & 61.5 \\
\hline
\end{tabular}

Table (3): Relationship between type of diabetic coma, type of DM, period of diabetes and place of management of coma

\begin{tabular}{|c|c|c|c|c|c|}
\hline \multirow[t]{2}{*}{ Variables } & \multicolumn{2}{|c|}{ Type of diabetic coma } & \multirow{2}{*}{$\begin{array}{l}\text { Total } \\
(\mathrm{N}=65)\end{array}$} & \multirow{2}{*}{$\begin{array}{l}\text { Chi- } \\
\text { Square } \\
\text { value }\end{array}$} & \multirow{2}{*}{$\begin{array}{l}\mathrm{P} \\
\text { value }\end{array}$} \\
\hline & $\begin{array}{l}\text { Hyperglycemic } \\
(\mathrm{N}=19)\end{array}$ & $\begin{array}{l}\text { Hypoglycemic } \\
(\mathrm{N}=19)\end{array}$ & & & \\
\hline \multicolumn{6}{|l|}{ Type of DM } \\
\hline \multirow{2}{*}{ Type I } & 8 & 23 & 31 & \multirow{4}{*}{0.336} & \multirow{4}{*}{0.562} \\
\hline & $42.1 \%$ & $50.0 \%$ & $47.7 \%$ & & \\
\hline \multirow[t]{2}{*}{ Type II } & 11 & 23 & 34 & & \\
\hline & $57.9 \%$ & $50.0 \%$ & $52.3 \%$ & & \\
\hline \multicolumn{6}{|l|}{ Period of diabetes } \\
\hline \multirow[t]{2}{*}{$<1$} & 0 & 5 & 5 & \multirow[t]{10}{*}{9.053} & \multirow[t]{10}{*}{0.060} \\
\hline & $.0 \%$ & $10.9 \%$ & $7.7 \%$ & & \\
\hline \multirow[t]{2}{*}{$1-$} & 6 & 5 & 11 & & \\
\hline & $31.6 \%$ & $10.9 \%$ & $16.9 \%$ & & \\
\hline \multirow[t]{2}{*}{$5-10$} & 3 & 10 & 13 & & \\
\hline & $15.8 \%$ & $21.7 \%$ & $20.0 \%$ & & \\
\hline \multirow[t]{2}{*}{$>10$ years } & 5 & 21 & 26 & & \\
\hline & $26.3 \%$ & $45.7 \%$ & $40.0 \%$ & & \\
\hline \multirow[t]{2}{*}{ Don’t know } & 5 & 5 & 10 & & \\
\hline & $26.3 \%$ & $10.9 \%$ & $15.4 \%$ & & \\
\hline \multicolumn{6}{|c|}{ Place of management of coma } \\
\hline \multirow[t]{2}{*}{ Admitted in the hospital } & 2 & 3 & 5 & \multirow[t]{6}{*}{1.311} & \multirow[t]{6}{*}{0.519} \\
\hline & $10.5 \%$ & $6.5 \%$ & $7.7 \%$ & & \\
\hline \multirow[t]{2}{*}{ In the emergency department } & 4 & 16 & 20 & & \\
\hline & $21.1 \%$ & $34.8 \%$ & $30.8 \%$ & & \\
\hline \multirow[t]{2}{*}{ At home } & 13 & 27 & 40 & & \\
\hline & $68.4 \%$ & $58.7 \%$ & $61.5 \%$ & & \\
\hline
\end{tabular}




\section{DISCUSSION}

DM is a metabolic disease of multiple etiologies, characterized by hyperglycemia resulting from defects in insulin secretion, insulin action or both, and associated with disturbance of carbohydrate, fat and protein metabolism ${ }^{[1]}$. It is one of the most common chronic diseases today, both in developed and in developing countries. According to recent estimates of the World Health Organization (WHO), 422 million people in the world had diabetes in 2014, and the prevalence of people with diabetes is expected to double between the years 2000 and 2030 $[2,3]$

This cross sectional study was carried out among 113 diabetic patients Arar, KSA. The study aimed at determining the prevalence of diabetic coma among the studied diabetic patients and to illustrate the relationship between type of diabetic coma and type of DM, period of diabetes and place of management of coma.

As regards to types of diabetes mellitus, our study reported $53.1 \%$ of studied diabetic patients had type II diabetes mellitus and $46.9 \%$ had type I. In Saudi Arabia a descriptive review was conducted to review and analyze studies reporting the incidence and prevalence rates of diabetes [11]. Two studies reported the prevalence rates of T1DM in Dhahran, Eastern KSA ${ }^{[12]}$ and in Al Madina, North West $\mathrm{KSA}^{[13]}$; the prevalence rates of T1DM were very similar, 27.52 and 26.7 per 100,000 respectively. A study conducted in Riyadh found that prevalence of T2DM was $31.6 \% \%^{[14]}$. In Jeddah another study reported prevalence of T2DM of $30 \%{ }^{[15]}$. Another study conducted among 380 diabetic patients of these, $102(26.8 \%)$ had type I diabetes mellitus, and $278(73.2 \%)$ had type II ${ }^{[16]}$.

In Riyadh a cohort study carried out among 9,149 adult Saudis,The overall crude prevalence of DMT2 was $23.1 \%{ }^{[14]}$.In England a population-based study found that; prevalence of total diabetes for all persons in England was $4.41 \%$, Type 2 diabetes was estimated to affect $(92.3 \%)$ of person and Type 1 diabetes $(7.7 \%)^{[17]}$.In South India a study among 545 patients $<30$ years of age yielded $314(58 \%)$ with $\mathrm{T}_{2} \mathrm{DM}^{[18]}$.

According to diabetic complications our study reported, Diabetic retinopathy $23.9 \%$, Diabetic neuropathy $10.6 \%$, Diabetic nephropathy $3.5 \%$ and Diabetic foot $2.7 \%$.A systematic literature review of papers published on diabetes prevalence and complications in North Africa ${ }^{[19]}$ found that, the prevalence of retinopathy ranged from $8.1 \%$ in Tunisia ${ }^{[20]}$ to $41.5 \%$ in Egypt ${ }^{[21]}$; nephropathy ranged from $6.7 \%$ in hospital outpatient clinics in Egypt ${ }^{[21]}$ to $46.3 \%$ in hospital inpatients in Egypt.
The prevalence of diabetic neuropathy ranged from $21.9 \%$ in hospital outpatient clinics to $60 \%$ in hospital inpatient clinics in Egypt [21]. High prevalence of neuropathy was also found in Sudan with a prevalence of $31.5 \%$ in hospital inpatient clinics to $36.7 \%$ in outpatient clinics, respectively ${ }^{[17,18]}$. In urban China a cross-sectional hospital based survey reported the prevalence of neuropathy, nephropathy, ocular lesions and diabetic foot disease were $17.8 \%, 10.7 \%, 14.8 \%$ and $0.8 \%$, respectively ${ }^{[16]}$ Another study carried out among 1414 subjects with diabetes, the prevalence of diabetic retinopathy was $4.8 \%$, and that of diabetic nephropathy and neuropathy was $10.5 \%{ }^{[20]}$.In Korea a study conducted among 1442 diabetic patients reported neuropathy $(24.2 \%)$, retinopathy $(24.0 \%)$, and nephropathy $(15.5 \%)^{[19]}$.

As regards to diabetic coma, our study found that $57.5 \%$ of patients had diabetic coma from them $70.7 \%$ had hypoglycemic coma and $29.2 \%$ had hyperglycemic. Another study reported, hyperglycemia was present in $38 \%$ of the patients and hypoglycemia in $12 \%{ }^{[14]}$. A national survey of 44 U.S hospitals, data were derived from two sources: the University Health System Consortium (UHC) Diabetes Benchmarking Project and VHA, Inc; hyperglycemia was present in $38 \%$ percent of the UHC cohort and 18\% of the VHA, in cohort, hypoglycemia to $<60 \mathrm{mg} / \mathrm{dl}$ was also common, with $12 \%$ of patients in the UHC cohort and $18 \%$ in the VHA $^{[13]}$.

\section{CONCLUSION AND RECOMMENDATIONS}

The prevalence of diabetic coma among the studied diabetic patients was $57.5 \%$ and the type of coma was hypoglycemic in $70.7 \%$ and hyperglycemic in $29.3 \%$. We recommend spreading the awareness among the diabetic patients about causes and manifestations of diabetic coma to avoid health risks and unacceptable complications . Also we recommend a large scale and more detailed researches.

\section{REFERENCES}

1. American Diabetes Association (2010): Diagnosis and classification of diabetes mellitus Diabetes Care, 33 (1): S62-S69.

2. Bellamy L, Casas JP, Hingorani AD (2009): Type 2 diabetes mellitus after gestational diabetes: a systematic review and meta-analysis. Lancet, 373:1773-1779.

3. Roglic W, Sicree G, King H (2004): Global prevalence of diabetes: estimates for the year 2000 and projections for 2030, Diabetes Care, 27(5):1047-1053. 
Hyper- and Hypoglycemic Coma...

4. Bos M, Agyemang C (2013): Prevalence and complications of diabetes mellitus in Northern Africa, a systematic review. BMC Public Health, 25:13:387.

5. Harzallah F, Ncibi N, Alberti H et al.(2006): Clinical and metabolic characteristics of newly diagnosed diabetic patients: experience of a university hospital in Tunis. Diabetes Metab., 32(6):632-635.

6. Herman WH, Aubert RE, Engelgau MM et al. (1998):Diabetes Mellitus in Egypt. Diabetes Mellitus in Egypt: glycaemic control and microvascular and neuropathic complications. Diabet Med., 15(12):10451051.

7. Liu Z, Fu C, Wang Wet al. (2010):Prevalence of chronic complications of type 2 diabetes mellitus in outpatients - a cross-sectional hospital based survey in urban China. Health and Quality of Life Outcomes, 8:62.

8. Abdulellah A, Lin P, Leila G et al. (2017): Incidence and prevalence rates of diabetes mellitus in Saudi Arabia: An overview. Journal of Epidemiology and Global Health, 7(3):7-14.

9. Abduljabbar M, Aljubeh J, Amalraj A et al. (2010): Incidence trends of childhood type 1 diabetes in eastern Saudi Arabia Saudi Med J., 31 (4):413-418.

10.Habeb A, Al-Magamsi M, Halabi $S$ et al. (2011):High incidence of childhood type 1 diabetes in Al-Madinah, North West Saudi Arabia (2004-2009). PediatrDiab., 12(8):676-681.

11.Al-Daghri N, Al-Attas O,Alokail M et al. (2011):Diabetes mellitus type 2 and other chronic noncommunicable diseases in the central region, Saudi Arabia (Riyadh cohort 2): a decade of an epidemic. BMC Med., 9(1):1-2.

12.Alqurashi K, Aljabri K, Bokhari S et al. (2011): Prevalence of diabetes mellitus in a Saudi community. Ann Saudi Med. ,31(1):17-19.

13. Dyck P, Kratz K, Karnes J et al. (1993): The prevalence by staged severity of various types of diabetic neuropathy, retinopathy, and nephropathy in a population-based cohort study. Neurology, 43(4):8-17.

14. Forouhi N, Merrick D, Goyder E et al. (2001):Diabetes prevalence in England, 2001estimates from an epidemiological model N.Diabetes UK. Diabetic Medicine, 23(2):189-197

15. Ramachandran A, Mohan V, Snehalatha C et al. (1988):Clinical features of diabetes in the young as seen at a diabetes center in south India. Diabetes Res ClinPract., 4(1):117-125.

16. Hamed SA, Amine NF, Galal GM et al. (2008): Vascular risks and complications in diabetes mellitus: the role of helicobacter pylori infection. Stroke Cerebrovasc Dis., 17(2):86-94.

17.Elmahdi EM, Kaballo AM, Mukhtar EA (1991): Features of non-insulin-dependant diabetes mellitus (NIDDM) in the Sudan. Diabetes Res ClinPract., 11(1):59-63.

18. Elbagir MN, Eltom MA, Mahadi EO et al. (1995):Pattern of long-term complications in Sudanese insulin-treated diabetic patients. Diabetes Res ClinPract., 30(1):59-67.

19. Deborah J, James B, Enrico C et al. (2007): Prevalence of Hyper- and Hypoglycemia Among Inpatients With Diabetes. Diabetes Care, 30(2) 367369.

20.Raman $\mathrm{R}$, Gupta A, Krishna $\mathrm{S}$ et al. (2012):Prevalence and risk factors for diabetic microvascular complications in newly diagnosed type II diabetes mellitus. SankaraNethralaya Diabetic Retinopathy Epidemiology And Molecular Genetic Study. Journal of Diabetes and Its Complications, 26(2): 123-128.

21. Tai H, Ho J, Pil W et al. (1987): The Prevalence of Diabetic Complications in Korea.Korean J Intern Med., 2(1): 4-42.

22.Pinhas-Hamiel O, Zeitler P (2005): The global spread of type 2 diabetes mellitus in children and adolescents. J Pediatr., 146(5):693-700. 